\title{
(C) OPEN ACCESS \\ How to communicate with patients about future illness progression and end of life: a systematic review
}

\author{
Ruth Parry, Victoria Land, Jane Seymour
}

- Additional material is published online only. To view please visit the journal online (http://dx.doi.org/10.1136/ bmjspcare-2014-000649).

Sue Ryder Care Centre for the Study of Supportive, Palliative and End of Life Care, School of Health Sciences, University of Nottingham, B Floor Queen's Medical Centre, Nottingham, UK

\section{Correspondence to}

Dr Ruth Parry, Sue Ryder Care

Centre for the Study of

Supportive, Palliative and End of Life Care, School of Health Sciences, University of Nottingham, B Floor Queen's Medical Centre, Nottingham NG7 2HA, UK;

ruth.parry@nottingham.ac.uk

Received 6 January 2014 Revised 18 June 2014

Accepted 24 August 2014

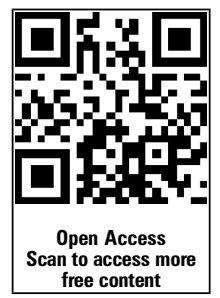

CrossMark

To cite: Parry R, Land V, Seymour J. BMJ Supportive \& Palliative Care 2014;4:

331-341.

\section{ABSTRACT}

Background Conversation and discourse analytic research has yielded important evidence about skills needed for effective, sensitive communication with patients about illness progression and end of life.

\section{Objectives To:}

- Locate and synthesise observational evidence about how people communicate about sensitive future matters;

- Inform practice and policy on how to provide opportunities for talk about these matters;

- Identify evidence gaps.

Design Systematic review of conversation/ discourse analytic studies of recorded interactions in English, using a bespoke appraisal approach and aggregative synthesis.

Results 19 publications met the inclusion criteria. We summarised findings in terms of eight practices: 'fishing questions' - open questions seeking patients' perspectives (5/19); indirect references to difficult topics (6/19); linking to what a patient has already said-or noticeably not said (7/19); hypothetical questions (12/19); framing difficult matters as universal or general (4/19); conveying sensitivity via means other than words, for example, hesitancy, touch (4/19); encouraging further talk using means other than words, for example, long silences (2/19); and steering talk from difficult/negative to more optimistic aspects (3/19).

Conclusions Practices vary in how strongly they encourage patients to engage in talk about matters such as illness progression and dying. Fishing questions and indirect talk make it particularly easy to avoid engaging - this may be appropriate in some circumstances. Hypothetical questions are more effective in encouraging ontopic talk, as is linking questions to patients' cues. Shifting towards more 'optimistic' aspects helps maintain hope but closes off further talk about difficulties: practitioners may want to delay doing so. There are substantial gaps in evidence.

\section{BACKGROUND}

There is consensus that people who are frail or have a specific terminal diagnosis should be provided with opportunities to discuss their future care and treatment preferences. $^{1-3}$ Conversations about these matters form part of advance care planning discussions-these aim to help individuals anticipate how their condition may affect them in the future and, if they wish, to set on record their preferences, choices and advance decisions to refuse treatment. ${ }^{4}$ However, there is evidence that in practice, patients and healthcare professionals rarely discuss future difficulties and plans. ${ }^{56}$ Surveys of clinicians have found that they report lack of confidence, skills and knowledge about how to initiate such discussions, making them reticent to do so. ${ }^{7}$ Clinicians also report that these conversations can be uncomfortable and challenging, ${ }^{8}$ with difficulties including ascertaining patients' preferences, and deciding on the 'right time' to raise such matters. ${ }^{7}$ These challenges are exacerbated by patients' and their companions' own reticence and ambivalence with regard to initiating these conversations. ${ }^{7}$ Clinicians want $^{9}$ and need ${ }^{10}$ more evidence-based guidance on optimal strategies for communicating about these matters with patients and their significant others. While practitioners are encouraged to provide those who consult them with opportunities to engage in advance care planning, guidelines also stress that this should be a voluntary engagement, ${ }^{4}$ and there is evidence that some patients strongly prefer not to discuss such matters. ${ }^{11}$ Practitioners thus also need to know how to sensitively ascertain and respond to patients' preferences in this regard.

In terms of precisely how to go about these conversations, a highly relevant body of evidence has been produced by 
studies that use the communication science approaches of conversation analysis ${ }^{12}$ and discourse analysis. ${ }^{13}$ These techniques involve inductively analysing audio or audiovisually recorded naturalistic interactions (rather than simulated or experimental ones). Conversation analytic studies are particularly useful because they entail analysing 'sequences'-that is, how what is said affects what happens next, also because they allow systematic analysis not just of what is said, but also how it is said-including intonation, pauses, gaze and gestures. ${ }^{12} 14$ Doing so generates detailed understandings about communication practices and how they function at a level of detail unavailable through qualitative interview studies of communication, ${ }^{14}$ but to date findings have not been incorporated into clinical guidance and training.

Our aim was to gather and synthesise evidence from conversation and discourse analytic studies of how people address difficult and uncertain future matters in their healthcare-related conversations. By difficult and uncertain future matters, we mean future difficulties in one's personal life, future illness progression, loss of capacity, dying and death. To avoid cumbersome wording, we refer to these as 'difficult future topics'; also, we refer to 'patients', although most of the evidence also applies to ways in which patients' significant others communicate. The overall purpose of the review was to inform practice, education and training in clinical decision-making and communication. We designed our review so as to locate and synthesise studies conducted in a wide range of healthcare-related contexts. We did so because of the recognition that people use highly systematic and recurrent practices and conventions for communicating with one another: it is because of their shared and ubiquitous character that we can understand and communicate with people we have never met before, in situations we have never been in before. Thus, each unique communication episode-be it a telephone call with one's parents, a counselling session or a medical consultation-is built on a bedrock of common practices for conversing together in an orderly and meaningful way. ${ }^{15}$ While the specific content of our communication is unique to each interaction, the practices people use to 'handle' this content are recurrent and shared. Recognising this, we cast our net wide when gathering evidence about how people talk about difficult and uncertain future matters in the context of healthcare. When synthesising the evidence we found, we focused specifically on its implications for communicating about illness progression and end of life.

\section{METHODS}

We drew extensively on existing systematic review approaches, but revised these and developed additional procedures because the methods and findings of conversation and discourse analytic studies differ considerably from both quantitative and qualitative research approaches. A detailed report of our methodological approach has been published, ${ }^{16}$ and includes discussion of the reasoning and rationale underpinning our methods and choices. We drafted a protocol on the basis of contemporary guidance, ${ }^{17} 18$ refined it in discussion with academics, practitioners and trainers, and registered it on the PROSPERO database. $^{19}$

\section{Study selection}

We included peer-reviewed journal articles and published book chapters reporting conversation and discourse analyses of audio or audiovisually recorded naturalistic interactions in English. Studies relying solely on coding frameworks were excluded. We included only studies where both data and analysis concerned communication about sensitive future matters. We sought studies where the talk was healthcare-related in both professional settings, for example, clinics, general practice surgeries, counselling; and informal ones, for example, family telephone calls. We included both conversation analytic and discourse analytic studies. As we have discussed elsewhere, ${ }^{16}$ discourse analysis is an umbrella term encompassing a wide range of approaches to analysing texts and talk-including qualitative content analysis. In contrast, conversation analysis is a single, defined and bounded research approach with a specific conceptual basis and method. As noted, an important distinguishing feature and advantage of conversation analysis is that the sequential analysis entailed allows empirical evidencing of the interactional consequences of particular practices. This means that conversation analytic research can show that particular ways of, for instance, asking about a patient's concerns, or making a treatment recommendation, are recurrently followed by particular responses from patients.

One reviewer (VL) carried out the search and initial screening of titles and abstracts, excluding clearly irrelevant publications at this stage. The remaining publications were independently considered for inclusion by two reviewers (VL and RP), resolving disagreements by discussion.

\section{Information sources}

We searched diverse sources ${ }^{17}{ }^{20}$ : existing knowledge within the review team and its contacts; online discussion lists; online specialist bibliographies; and the citations and reference lists of the publications we identified through other means. The electronic databases searched were: ISI Web of Science, Amed, EMBASE, CINAHL, MEDLINE, PsycINFO, ASSIA, Sociological Abstracts CSA and Scopus. We did not restrict the date of publication. A first round of electronic database searching was completed on 25 May 2011; a second round, updating the first, was completed on 1 May 2014. The search strategy is available online. $^{21}$ 


\section{Data collection, appraisal and synthesis}

We developed, piloted and refined a data extraction form. This is available online, ${ }^{21}$ as is a form used in assessing the characteristics and contribution of individual studies. ${ }^{21}$ As we have discussed elsewhere, ${ }^{16}$ the kind of research we reviewed needs to be appraised in terms of two broad dimensions: (1) the type and amount of data analysed, and (2) the detail and depth of analysis. Some studies involve examining a relatively small amount of data in great depth and provide highly detailed evidence about the structure, locations, functioning and mechanism of a particular practice. Some studies entail a less detailed analysis of structure and functioning, but nevertheless contribute evidence about how widespread and recurrent a practice is. We synthesised the extracted data using an aggregative approach, drawing together findings through structured summaries and comparing and connecting findings with one another. ${ }^{22}$ We developed and refined emerging findings by discussing them and their potential implications with clinician and educator audiences.

\section{RESULTS}

Of 2887 records obtained, 19 publications ${ }^{23-41}$ reporting findings from 13 research programmes met the inclusion criteria. (These figures differ slightly from earlier reports ${ }^{16}{ }^{42}$ because our updating search in 2014 yielded two further studies ${ }^{23} 29$ for inclusion, and because we removed one publication ${ }^{43}$ initially included as it lacked a healthcare context.) The flow chart in figure 1 enumerates the publications identified, excluded and included. Ten of the 19 included papers concerned medical consultations: inpatient palliative care team consultations ${ }^{29}$; cardiology $^{23}$; oncology clinics ${ }^{25} 2633{ }^{34}$; primary care ${ }^{27} 40$ and gender identity psychiatric assessment. ${ }^{38} 39$ Seven were on counselling sessions: $\mathrm{HIV}^{30-32}{ }^{37}$ genetics, ${ }^{35}{ }^{36}$ and combined HIV and family therapy data sets. ${ }^{28}$ There was one study each from: family telephone conversations, ${ }^{24}$ and informed consent appointments for a randomised controlled trial. ${ }^{41}$

Online supplementary table S1 summarises each study's characteristics, including the type, amount and range of the data on which the analysis was based, and the depth and detail of the analytic techniques applied. In all but the family phone calls study, analysis was largely focused on professionals' communication behaviours and patients' responses to these. Analysis in three publications ${ }^{33} 3440$ only examined individual spoken turns, and did not systematically analyse how they were responded to. In two others, there was some limited attention to sequencing in terms of how clinicians' practices shaped and related to how patients responded, and most of the empirical data shown in these publications comprised clinicians' talk. $^{23} 29$ In the remaining 14 publications, analysis examined in varying degrees of depth the structure, functioning and mechanism of communication practices by examining sequences of talk. In 9 publications, analysis examined only the word content, that is, what was said; in the other 10 , analysis examined other aspects, that is, how it was said-including intonation, volume, hesitancy and pauses-aspects known to be important in how people convey meaning within their own communications and make sense of what others say. ${ }^{14}$ Several studies used video data, but only one ${ }^{26}$ attended to body movement (eg, gaze or touch), and even then only very briefly.

Two papers specifically examined communication in relation to aspects of specialist palliative care ${ }^{29}$ and advanced care planning, ${ }^{23}$ settings which are particularly relevant to the overall purpose of our review. Unfortunately, some features of these studies reported meant that they were only able to make a limited contribution to our review: the data comprised audio rather than audiovisual recordings; the qualitative analytic approaches used meant that the detail about practices' structure and functioning was less finegrained than is possible via conversation analytic methods; and limited information was provided about the prevalence and recurrence of the identified practices.

Details of individual study findings are given in online supplementary table S2. We sorted communication practices that had been documented in two or more publications into categories. These spanned practices used in initially broaching or attempting to elicit talk on difficult future issues, those used in progressing talk on the topics once they had been raised, and those which closed the topics. While for the purposes of this review we synthesised findings into discrete sets of practices, it is worth noting that in the real world, of course, professionals improvise and apply communication practices in numerous combinations. ${ }^{44}$ The eight categories of practices are summarised in box 1 ; in the text, we describe them in more detail and give some illustrative examples.

\section{Fishing questions}

The practice of asking fishing questions is documented in studies from counselling 28313239 and oncology $^{26}$ contexts. Often coming towards the start of conversations, these are open questions-in the sense that they do not give any pointers towards answers that specifically concern difficult future topics: for example, Counsellor: "Graham, are there any issues you'd like to discuss?" (Extract 8$)^{32}$; "Can I just ask you what are your greatest concerns Liz?" (Extract 1). ${ }^{31}$ This question structure allows patients easily to avoid embarking on the difficult future topics by answering in terms of other matters. We term these fishing questions because of the way they fish for, but do not directly target, responses about difficult future topics. Studies examining the structure and functioning of fishing questions in the greatest detail ${ }^{26} 32$ 


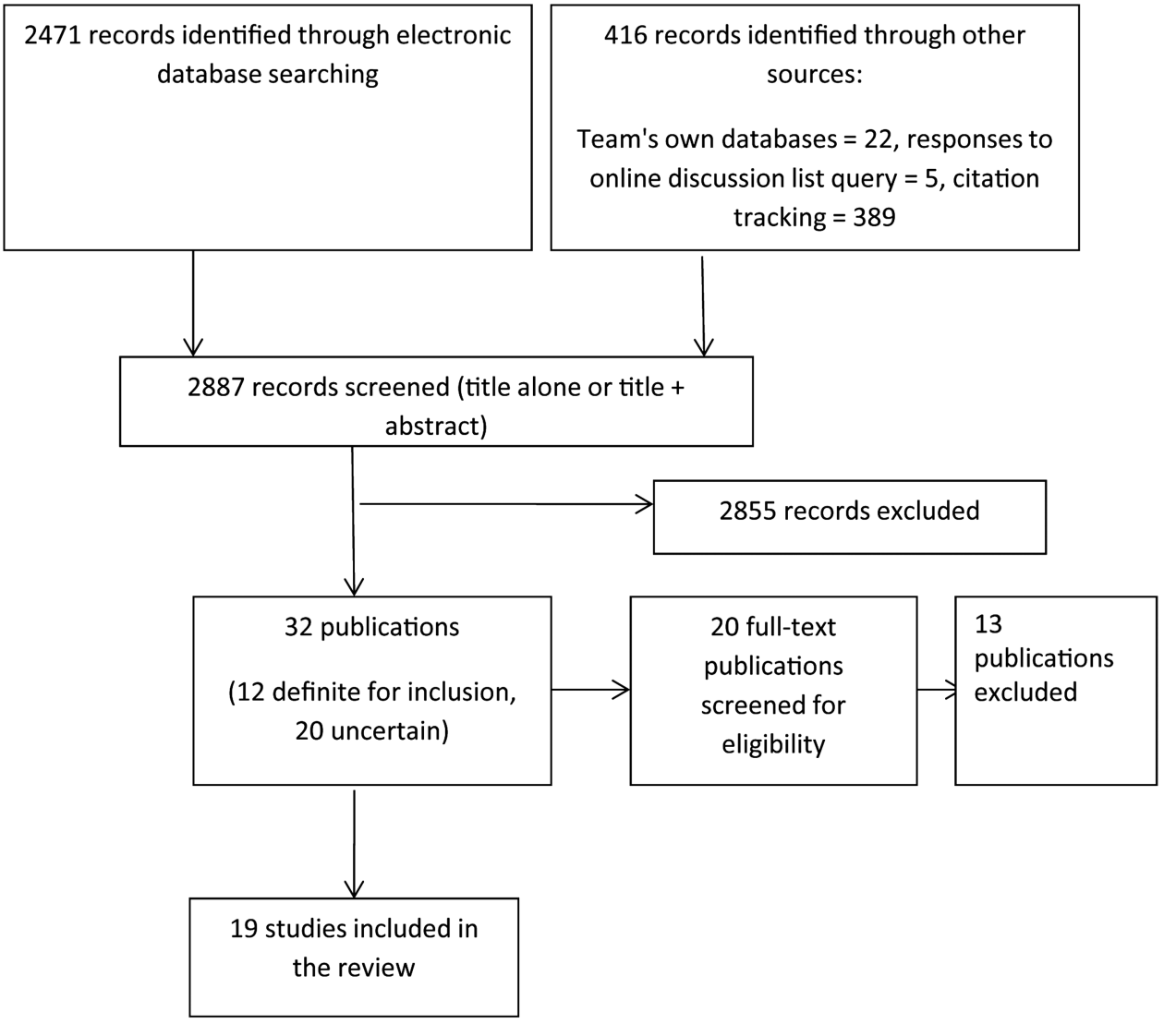

Figure 1 Study screening.

suggest that they are usually ineffective in eliciting talk about difficult future matters. However, it is argued ${ }^{32}$ that there is nevertheless a rationale for using themif the patient does opt to answer in terms of the difficult future topics, then this puts on record their personal commitment to talk about the topic(s), and this would not be the case were the professional to be the first to raise them.

\section{Indirectness, allusive talk and euphemisms}

Four publications from oncology consultations, ${ }^{26} 333440$ one from primary care ${ }^{27}$ and one from cardiology ${ }^{23}$ examine indirect, allusive, euphemistic and vague forms of talk. This category encompasses various means by which both professionals and those who consult them refer to difficult future topics in an indirect manner. One of these involves doctors and patients focusing on treatment outcomes rather than disease outcomes, $33-34$ for example, Oncologist to a patient with terminal cancer: "I know that the surgical doctors have been pretty happy with how quickly you've recovered" (Extract 1A). ${ }^{26}$ Other practices include referring to topics that are associated with illness progression and end of life but not directly on-topic-for instance, hospice $\operatorname{care}^{26}$; using euphemisms for death, for example, 'pushing up daisies ${ }^{33}$; and using various forms of talk that allow patients to draw their own conclusions through: (A) expressing emotional concerns and hinting at difficult future developments: for example, Oncologist: "I'm concerned that, you know, there's a possibility that things might not go so well for you" (Extract $1 \mathrm{D})^{26}$; (B) referring to palliative rather than curative treatment; and $(\mathrm{C})$ phrases known as litotesthese suggest the worse scenario by negating the better scenario, for example, Oncologist: "Do you think there's a possibility that you might not get better?" (Extract $1 \mathrm{C})^{26}$ - perceptibly less harsh than alternatives such as "Do you think you might get worse/die?". Another well-documented form of indirect talk used by both doctors and patients involves impersonal reference, for example, referring to the disease as ' $I t$ ' or 'That' 2634 rather than 'My disease' or 'Your disease'; and avoiding direct reference to the individual patient, for example, Oncologist: "We can rarely cure this type of problem. What we can do, though, is shrink the mass. It will sometimes go away completely, and we can increase the life span and the quality of life, but the tumor will usually come back." 33

Only one study ${ }^{26}$ analyses the effects of indirect talk in terms of how it gets responded to, and whether and how it promotes or limits talk on the difficult future topics. (Notice that this particular study examined indirect talk used in a doctor's early moves towards difficult future topics, not occasions where doctors gave indirect responses to patients' direct questions.) This study found that patients responded 
FISHING QUESTIONS

Opening questions which seek patients' perspectives and which may or may not hint at possible difficult topics via terms like 'concerns' or 'problems', and which do not specifically refer to difficult future topics.

Functioning: patients rarely provide responses that bring topics such as illness progression, imminence of end of life, etc. to the surface, that is, these questions rarely 'catch the fish'.

Documented in five publications. ${ }^{26} 28313239$

INDIRECTNESS, ALLUSIVE TALK AND EUPHEMISMS

Referring to difficult future topics indirectly via practices such as: referring to outcomes of treatment rather than outcomes of illness, euphemisms, expressing emotional concern for patient, referring to 'it' or 'that', to getting 'very, very ill' or to 'something serious', referring to people in general rather than this particular patient. Patients respond by shifting away from the topic, or by displaying stoicism - with little verbal response, or by showing some understanding of the underlying difficult future topic. ${ }^{26}$ When the latter two response types occur, the professional can then move progressively towards more direct engagement with the difficult future topics. ${ }^{26}$

Functioning: can encourage engagement with the topics, and can be early moves in a trajectory towards greater openness. At the same time, they make it particularly easy for patients to deflect away from the difficult topics. For this reason, indirectness may be a useful way to gently ascertain whether a patient prefers not to discuss these matters (yet), and to abide by this preference.

Documented in six publications. ${ }^{23} 2627333440$

LINKING QUESTIONS AND PROPOSALS TO WHAT THE PATIENT HAS SAID OR NOT SAID

When posing a question, or repeating or rephrasing an unanswered question, or making proposals about future plans, the professional refers back to something the patient has already raised or hinted at, or has noticeably not said.

Functioning: This treats the patient as already having shown that the difficult future topics are relevant and thus something they want to and should engage with. It allows the practitioner to show that they have been paying attention to the patient, and to selectively focus in on difficult future topics. Documented in seven publications. ${ }^{28-32} 3941$

HYPOTHETICAL QUESTIONS AND TALK

Hypothetical questions entail describing a hypothetical future situation then enquiring about related feelings or plans. Hypothetical talk is phrased hesitantly and sensitively, and in ways that: (A) convey it as touched off by or connected with what the patient has already said, and (B) emphasise its hypothetical nature.

Functioning: Patients usually respond by engaging with the difficult future topics.

Documented in 12 publications. ${ }^{23} 262830-32$ 35-40

FRAMING THE DIFFICULT ISSUE AS UNIVERSAL OR GENERAL RATHER THAN INDIVIDUAL TO THIS PATIENT

The difficult future situation is framed as universal, as something anyone could face.

Functioning: Its effectiveness in encouraging talk about difficult future topics is not examined in existing evidence. However, it seems probable that, like hypothetical talk, this downplays or distances the reality and seriousness of the difficult issues for this individual patient, thereby making it more likely that patients will engage with the topics.

Documented in four publications. ${ }^{31} 333437$

COMMUNICATION PRACTICES OTHER THAN WORDS THAT CONVEY SENSITIVITY

Delays, hesitations and turbulence, for example, stuttering and repeats when broaching and talking about the difficult issues. Both professionals and patients do so. One study ${ }^{30}$ provides evidence that when doctors' talk is turbulent, patients sustain close attention to the doctor.

Functioning: This kind of talk conveys the sensitivity and seriousness of the topics.

Documented in four publications. ${ }^{26} 303137$

Also within this category is touch, which is only mentioned in one study. ${ }^{26}$ This describes how a doctor touches a patient's hand at the same time as indirectly talking about difficult future issues.

Functioning: Touch may convey support and comfort while also conveying the seriousness of the topic(s). However, patients' responses have not been empirically studied.

COMMUNICATION PRACTICES OTHER THAN WORDS THAT ENCOURAGE PATIENTS TO TALK ONCE THE TOPIC HAS BEEN BROACHED

Once a difficult future topic has been raised by a professional via some form of question, they avoid producing further talk until the patient has responded-even if this means leaving gaps of silence longer than is common in regular conversations. Also, once the patient has begun to respond, the clinician speaks only briefly and in ways that encourage the patient to continue, for example, by saying ' $M m$ '.

Functioning: Generally, people have a low tolerance for silences within conversations, so this encourages patients to talk on the difficult issues.

Documented in two publications. ${ }^{37} 41$

continued 
Shifting to the positive

'Upbeat' talk of various forms: referring to fighting, perseverance and hope, facing illness together, giving optimistic rather than pessimistic versions, and referring to treatment success as opposed to overall trajectory of the illness. Both patients and professionals do so. One paper ${ }^{25}$ documents a recurrent pattern wherein oncologists follow bad or uncertain news with relatively hopeful or positive news, and patients respond by focusing on the latter, positive element.

Functioning: Upbeat talk conveys optimism and hope and also contributes to building and maintaining therapeutic relationships. But it can also suppress further talk on the difficult future topics, and thus limit engagement with them.

Documented in three publications. ${ }^{24} 2527$

to the doctor's indirect references to difficult future matters in three alternative ways: (1) shifting away from the sensitive future topic, (2) displaying stoic unresponsiveness and (3) responding in a way that reveals an understanding of the underlying concerns - such as illness progression. When patients gave stoic responses, or ones revealing some understanding and recognition, the doctor took the opportunity to progressively 'unpack' the alluded to matters in a step-by-step manner so that both the patient and doctor ended up talking more directly about the difficult future matters. ${ }^{26}$

In sum, the available evidence indicates that indirect talk is recurrent in medical consultations and is used by both doctors and those who consult them. It allows people to very easily avoid talking about the difficult topics for the following reason: when one talks indirectly about difficult issues, one avoids putting one's conversational partner in a position of having to voice some excuse for not taking them up. So, indirect talk gives people an easy route to deflect away from or avoid the difficult and sensitive topics that have been implied, and some patients and relatives do so. ${ }^{26}$ On the other hand, indirect talk can also function as the first step in a gradual progression towards directly talking about the difficult future issues.

\section{Overtly linking questions and proposals with what patients have already said, or have not said}

Studies in palliative care consultations, ${ }^{29}$ psychiatry, ${ }^{39}$ counselling settings ${ }^{28} 30-32$ and in drug trial recruitment $^{41}$ report that when professionals ask questions about topics related to difficult futures, they often preface their questions by explicitly referring back to what are sometimes termed patients' cues ${ }^{45}$ : something a patient has themselves raised or hinted at. One way to do $\mathrm{so}^{28} 30$ involves the professional first issuing a summary or interpretation of what the patient has said beforehand, and then asking a related question. Professionals do this when they pose new questions, when dealing with a patient's reluctance to answer a previous question, and when making proposals about future plans. Sometimes they link back to what a patient has mentioned immediately beforehand, sometimes to something said a good while earlier, for example, Counsellor: "What Michael mentioned initially is that you know he didn't have any concerns but he's been feeling funny again, is that a worry to him or is it no problem to him..." (Extract 19). ${ }^{32}$ Professionals can also make links to a matter noticeably absent from the patient's earlier talk, for example, Counsellor: "You haven't mentioned AIDS as a concern today. How much of a concern is it now?" (Extract 21). ${ }^{32}$ (This and some other examples are drawn from recordings made in HIV/AIDS clinics at a time when HIV constituted a terminal diagnosis.)

This linking practice has been documented to be effective in encouraging patients' engagement in talk about future issues. It works by making it difficult for a patient to avoid answering a question or talking about a plan because the question or plan is presented as something the patient has themselves raised-and thus should engage with. ${ }^{32}$ In addition, linking allows professionals to show their appreciation of, attention to, and agreement with what patients have said, ${ }^{28}$ and to avoid going on record as unilaterally imposing the difficult future topic on the conversation. ${ }^{31}$ When linking is used in the context of talking about plans for the future, it can work to construct an atmosphere of agreement and convey the patient as the one who has the lead responsibility in terms of making plans and proposals. ${ }^{28}$

\section{Hypothetical questions and talk}

Practices involving talking in hypothetical terms and posing hypothetical questions have been documented across several settings: cardiology clinics, ${ }^{23}$ counselling and psychiatry, ${ }^{28}{ }^{30-32} 3^{35-39}$ and oncology. ${ }^{26} 40$ The basic structure of a hypothetical question entails the speaker describing a hypothetical future situation and following this with an enquiry about associated perspectives, feelings or plans. The evidence indicates that these questions are highly effective in encouraging patients to engage with difficult issues. Specifically, this evidence relates to hypothetical questions that $\operatorname{are}^{31}:$ (1) posed part-way through conversations, usually after previously attempting to elicit talk 
on the difficult future topics through other practices such as fishing questions and/or indirect talk; (2) voiced carefully and hesitantly-thus conveying that what is talked about is both serious and sensitive; (3) phrased as touched off by or connected with what the patient has already said and (4) emphasised as being hypothetical in their nature. Thus, in the following example, the counsellor's first 'Say' is spoken in a long, stretched way and the hypothetical and uncertain nature of the talk is very much emphasised: Counsellor: "Saaaaaay, we can't say and you can't say,' Patient: 'Yeab' Counsellor: 'but say you did begin to get ill (pause) or say you got so ill that you couldn't kind of (pause) make decisions for yourself. Who would (pause) you have to make them for you? (pause) Who do you (pause) consider your..." (Extract $4)^{31}$; similar features can be seen here: Counsellor: "If you, if you-supposing- I mean this is just supposing, supposing you (pause) had got infected or were to get infected..." (Extract 8$){ }^{31}$

The evidence indicates that patients usually respond to hypothetical questions in ways that engage with the difficult future topics. Hypothetical questions are thus a powerful and effective tool for encouraging about difficult future topics and related concerns and plans. ${ }^{28}$ This seems to relate to the way that hypothetical questions downplay the connection between this particular patient and becoming unwell, dying, etc. By emphasising the imaginary nature of the circumstances depicted, a distance is created between this particular patient and the facts of illness progression, end of life, etc-and this distancing makes matters easier to talk about (a danger may be that any associated decisionmaking may also not seem 'real'-this has not been examined). Further insights into how hypothetical questions work are provided by evidence that in face-to-face communication, questions strongly oblige responses, and specifically they strongly oblige responses fitted to matters that the questioner has assumed and implied in the phrasing of their question. ${ }^{46}$ In contrast to fishing questions, hypothetical questions push hard for very specific and on-topic responses. Finally, it has been noted that hypothetical questions allow practitioners and patients to engage in talk about the future without either having to commit to accurate prognostication ${ }^{31}$ this is particularly useful in the light of the uncertain trajectories that frailty and life-limiting illnesses often take.

\section{Framing the issue as universal or general}

Two studies from counselling ${ }^{31} 37$ and two from oncology ${ }^{33} 34$ settings document practitioners referring to the difficult future topics as matters that anyone could face, framing them in terms of abstract rules or principles that concern or apply to everyone, for example, Counsellor: "Say, say you did die, what would be the hardest thing for your partner? Any of us can die in crashes or anything but just let's take it out, what would be the hardest thing for your partner?" (Extract 10, adapted). ${ }^{31}$ In another example, a counsellor prefaces a question about a sensitive and potentially distressing matter as follows: "And one of the things that we know we're sort of faced with sometimes when people get very ill and even die, is of course views about post-mortems in general and I just would like to know what Barry feels about that just in general?" (Extract 11). ${ }^{31}$ Generalising or universalising works, like hypothetical talk, to downplay the relevance of illness progression or dying to this particular patient. ${ }^{37}$ Extrapolating from this, it may be that framing issues as general or universal is, like hypothetical talk, effective in encouraging talk on the difficult future topics. However, this has not been empirically examined.

\section{Communications other than words that display sensitivity}

Three studies in counselling and one in an oncology setting $263031 \quad 37$ document that when people raise and pursue talk on difficult future topics, they generally do so with delays, hesitations and 'turbulence'that is, stuttering, cut-off words and repeats. One of the studies examined closely how patients respond to this kind of talk and found that patients sustain close attention over its course. ${ }^{30}$ The practices can be seen in the counsellor's talk within an example we have examined above; with regard to hypothetical questions, it includes slow, stretched out words and lots of pauses: "Saaaaaay, we can't say we can't say and you can't say... but say you did begin to get ill (pause) or say you got so ill that you couldn't kind of (pause) make decisions for yourself. Who would (pause) you have to make them for you? (pause) Who do you (pause) consider your..." (Extract 4$).{ }^{30}$ By talking in this way, people convey the sensitivity and also the seriousness of the matters they are talking about. This study also showed that these features have a special function when used within hypothetical questions: while talking about 'imaginary' matters downplays the seriousness and sensitive character of what is talked about, delivering hypothetical questions via hesitant and turbulent talk underlines the seriousness and sensitivity of the matters that are raised. Another practice within this category is touch. This has been subject to very little examination in this context; one study ${ }^{26}$ describes an episode in which a doctor touches a patient's hand at the same time as talking indirectly about difficult future issues, and suggests that this touch works to convey support or comfort while also conveying seriousness and sensitivity. However, we found no systematic analysis of touch and its effects on patients in this context.

\section{Communication practices other than words that encourage} the patient to talk once the topic has been broached

There is a small amount of evidence on this set of practices. ${ }^{37}{ }^{41}$ In one practice, after a professional has raised a difficult future topic by asking a patient a 
question, if the patient does not respond, the professional remains silent. There is evidence that this can result in the patient eventually engaging with the topic. In their everyday conversations, people rarely leave gaps of longer than $0.3 \mathrm{~s}$ after questions, ${ }^{47}$ and gaps of longer than a second are rare unless some other activity (eg, writing in notes) is occurring. ${ }^{48}$ That is, people have a low tolerance for silences in conversations, and thus silences can work to encourage talk. In another documented practice, once a patient has begun to respond to a question, the clinician speaks only briefly and in ways that encourage the patient to continue talking, for instance, only saying 'Mm'. A small amount of evidence suggests that these practices are effective in encouraging patients to talk on difficult future topics.

\section{Shifting to the positive}

Studies of family telephone calls, ${ }^{24}$ oncology ${ }^{25}$ and primary care ${ }^{27}$ show that once a difficult future topic has been broached, it is very common for patients, family members and doctors to move rapidly towards upbeat talk of various forms. These include referring to fighting, perseverance and hope, facing illness together, optimistic rather than pessimistic versions and treatment successes. One publication ${ }^{25}$ analyses in detail the interactional consequences of doing so. It documents a pattern in which the doctors studied immediately followed bad or uncertain news with relatively hopeful or positive news. ${ }^{25}$ The study shows that patients then respond to the last thing the doctor has said-that is, the patient stays on the optimistic topic and does not engage with what was mentioned first. In doing so, patients are following a conversational convention in which second speakers generally respond to the last thing the previous speaker has said. Upbeat talk and shifting to the positive build and convey optimism and hope, ${ }^{24}$ and play an important role in building and maintaining doctor-patient relationships. ${ }^{27}{ }^{34}$ However, shifting from negative topics to positive ones suppresses further talk on the difficult topics. ${ }^{30-44}$

\section{DISCUSSION}

We have examined a body of research that inductively analyses conversations and consultations via audio and audiovisual recordings. This kind of research generates explicit descriptions of communication practices and their outcomes. Such descriptions are important for evidence-based and reflective practice because they make explicit the communication practices that many clinicians use regularly, but about which their understandings reside largely in the tacit domain.

We identified and reviewed 19 publications, mostly analyses of conversations in clinical settings. A minority $(7 / 19$, see online supplementary table $S 1)$ had been written for clinical audiences. After excluding practices documented in only one publication, we collated findings into eight categories: 'fishing questions'open questions seeking patients' perspectives (5/19); indirect, allusive or vague talk (6/19); linking questions and proposals to what the patient has already said or noticeably not said (7/19); hypothetical talk (12/19); framing difficult matters as universal or general (4/19); conveying sensitivity and seriousness via means other than words, for example, hesitant talk, touch (4/19); using means other than words to encourage further talk, for example, leaving silences after questions (2/19); and steering talk from negative or difficult to more optimistic aspects (3/19). Importantly, these practices differ considerably in how strongly they encourage talk on sensitive topics. Although most analyses primarily examine practitioners' behaviours, there is some evidence that patients and their significant others use similar practices.

Our review was based on a carefully developed methodology ${ }^{16}$ which applied established conventions for systematic reviewing while also applying techniques specifically fitted to conversation and discourse analytic evidence. A key strength of the review is that it makes available to clinicians, policymakers and clinical educators evidence about communication that has been relatively inaccessible because of its publication in non-clinical fields, and its framing in terms of sociological and linguistic arguments and concepts. Weaknesses include the fact that we did not incorporate studies of conversations about difficult future issues in languages other than English. We did identify some publications in this category which would have been rated high in their quality and potential contribution to the review, ${ }^{49}$ but excluded them because of the possibility that different languages might entail subtly different practices for talking about the future and different consequences of these practices. Another weakness, evident in some of our illustrative examples, is the fact that some of the studies report on data that are now more than 20 years old. There is, however, good reason to assume that while contemporary clinical circumstances are different (particularly in relation to HIV/AIDS), language structures and their functioning are rather more stable matters ${ }^{12}$-this is evident in the way that the same communication practices are indeed reported in earlier and later studies. Finally, there are substantial gaps in evidence. These gaps mean that the review cannot provide a comprehensive overview of all the practices actually used in talking about difficult future issues. In particular, there are large gaps in knowledge about: practices used by patients, their companions and by healthcare professionals other than doctors and counsellors; and about the role of body movements such as touch. Also, only one study to date has examined practices used by specialists in palliative care $^{29}$-while this study makes a helpful contribution to understanding little-examined practices in a setting 
where talk about difficult future issues is a key part of the work, as we noted, its contribution to the review findings is limited because of the analytic approach applied. We strongly advocate the use of a conversation analytic approach ${ }^{12}$ in future studies, because of its capacity to yield fine-grained, systematically generated findings, and because its findings and claims are tightly tied to the details of the empirical data (what is said and how it is said), and to a cumulative body of established findings about the structure and functioning of communication practices. ${ }^{14}{ }^{15}$ Most of the currently available evidence concerns those stages in consultations and conversations wherein people are initially broaching difficult future topics and those where they are closing these conversations. There is very little on how people progress conversations from raising the difficult future topic to actually engaging in associated decision-making and planning.

The outcome of particular communication practices in terms of patients' experience of care, and their conduct subsequent to the consultation, is another area about which little is known as yet. Recent research by Robinson and colleagues has opened up new avenues. ${ }^{50}$ Using conversation analysis-derived coding, they were able to show that levels of hopelessness of patients significantly decreased after consultations, and that this change was associated with the occurrence of two particular communication behaviours: patients asserting their treatment preferences, and doctors providing good or hopeful news. This form of research, showing links between specific and carefully operationalised communication behaviours and patient outcomes, holds great promise for advancing healthcare communication practice and training.

Overall, further research is needed, in particular research that provides insights not just into healthcare professionals' communication, but also into the contributions of patients and their significant others, and into the outcomes of specific practices. Such analyses need to attend not just to what is said and done, but how it is said and done.

\section{Implications}

At the broadest level, the implications of our findings are that conversations about illness progression and end of life can be initiated and pursued in a variety of ways, and that these have different consequences. More specifically, fishing questions and indirect talk show sensitivity and can not only open up the topics, but also make it relatively easy for patients and others to avoid engaging with them. Thus, where a clinician judges that it is in the patient's and their significant others' best interests to raise the issue gently, to knock on the door rather than push at it, these practices seem optimal. Indirect talk may be useful when a clinician wishes to test whether this is 'the right time' to pursue these issues, although fishing questions less so because they so rarely elicit on-topic answers.
Hypothetical questions more strongly oblige on-topic talk, and there is good reason to suggest that framing concerns as general rather than specific to the individual will also do so. These practices are suited to circumstances where a clinician judges it is in a patient's best interests to more strongly encourage talk on the difficult future issues, for example, when a decision about whether or not to instigate an invasive intervention is imminent. Linking questions and proposals to patients' cues-matters they have already raised or hinted at (or even to matters a patient has noticeably not raised)-are effective in encouraging engagement with difficult future topics. Finally, shifting conversations towards more 'optimistic' aspects plays a role in maintaining hope, but because it also closes off further talk about difficulties, clinicians may want to delay doing so.

Although we report findings in terms of three further categories-framing issues as general, communication other than words that conveys sensitivity and communications that encourage patients to talk once a topic has been raised-we have not proposed specific implications in relation to these because there was very little evidence about these practices' structures and functioning.

Our review makes an important contribution to the evidence base for clinical decisions about 'what works and how' in terms of providing patients and their significant others with opportunities to communicate about difficult issues. This information should help raise clinicians' confidence in broaching these issues, and applying it to actual practice may increase the effectiveness of advanced care planning and end of life decision-making.

\section{CONCLUSIONS}

Much research, policy and commentary advocates providing opportunities for talking about difficult uncertain future issues including illness progression and end of life with patients who have long-term and serious illnesses, and with people who are frail and elderly. There are different ways to initiate talk about feelings and plans in relation to difficult topics like end of life-in particular, posing hypothetical questions strongly encourages on-topic talk, while indirect references to the difficult issues form a more gentle way of 'pushing at the door' of the topics-which some patients take up and some deflect. There is, however, much we still do not know, including about communication practices used in reaching decisions about future care, and about the role of bodily communication within these conversations.

Acknowledgements The review advisors were Merran Toerien and Paul Drew; they discussed the review purpose and design, and suggested publications for inclusion. A number of

audiences discussed our findings with us and helped shape the implications drawn; these include: the staff at LOROS Hospice Care in Leicestershire, members of the East Midlands Cancer Network, and those attending the Helsinki Collegium for 
Advanced Studies 2011 Symposium on Mortality and Emotions.

Funding The study was funded by the Sue Ryder Care Centre for the Study of Supportive, Palliative and End of Life Care at the School of Health Sciences, University of Nottingham (for RP's and JS's time) and by a small grant from the School of Health Sciences, University of Nottingham (for VL's time). The study sponsor was the University of Nottingham.

Contributors RP conceived and instigated the review and wrote the protocol, participated in the search and selection of publications and in data extraction, and led the synthesis and drafting of this manuscript. VL collaborated on the design of the review, conducted the majority of searches for publications and the majority of data extraction, supported the synthesis, commented on drafts of this manuscript and approved this submitted version. JS acted as consultant on the design and substantive topics of this review, commented on drafts of this manuscript and approved this submitted version.

\section{Competing interests None.}

Provenance and peer review Not commissioned; externally peer reviewed.

Open Access This is an Open Access article distributed in accordance with the Creative Commons Attribution Non Commercial (CC BY-NC 3.0) license, which permits others to distribute, remix, adapt, build upon this work noncommercially, and license their derivative works on different terms, provided the original work is properly cited and the use is non-commercial. See: http://creativecommons.org/licenses/by$\mathrm{nc} / 3.0 /$

\section{REFERENCES}

1 General Medical Council. Treatment and care towards the end of life: good practice in decision making. Ethical Guidance. London: General Medical Council. 2010. http://www.gmc-uk. org/guidance/ethical_guidance/end_of_life_care.asp

2 Gawande A. Letting go: What should medicine do when it can't save your life? The New Yorker 2010 (August 2nd):36-49. http://www.newyorker.com/reporting/2010/08/02/100802fa_ fact_gawande

3 Department of Health. End of life care strategy: promoting high quality care for all adults at the end of life. London: Department of Health, 2008. https:/www.gov.uk/government/ publications/end-of-life-care-strategy-promoting-high-qualitycare-for-adults-at-the-end-of-their-life

4 Seymour J; the advisory group to the Natonal End of Life Care Programme. Capacity, care planning and advance care planning in life limiting conditions: a guide for health and social care staff. Leicester: The National End of Life Care Programme, 2011.

5 Newbould J, Burt J, Bower P, et al. Experiences of care planning in England: interviews with patients with long term conditions. BMC Fam Pract 2012;13:71.

6 Abarshi E, Echteld M, Donker G, et al. Discussing end-of-life issues in the last months of life: a nationwide study among general practitioners. J Palliat Med 2011;14:323-30.

7 Almack K, Cox K, Moghaddam N, et al. After you: conversations between patients and healthcare professionals in planning for end of life care. BMC Palliat Care 2012;11:15.

8 Pontin D, Jordan N. Issues in prognostication for hospital specialist palliative care doctors and nurses: a qualitative inquiry. Palliat Med 2013;27:165-71.

9 Raijmakers N, van Zuylen L, Costantini M, et al. Issues and needs in end-of-life decision making: an international modified Delphi study. Palliat Med 2011;26:947-53.

10 Sleeman K. End-of-life communication: let's talk about death. J R Coll Physicians Edinb 2013;43:197-9.
11 Parker SM, Clayton JM, Hancock K, et al. A systematic review of prognostic/end-of-life communication with adults in the advanced stages of a life-limiting illness: patient/caregiver preferences for the content, style, and timing of information. J Pain Symptom Manage 2007;34:81.

12 Sidnell J, Stivers T. The handbook of conversation analysis. Malden, MA: Wiley-Blackwell, 2013.

13 Potter J. Discourse analysis and discursive psychology. In: Cooper H, ed. American Psychological Association handbook of research methods in psychology: Vol. 2. Quantitative, qualitative, neuropsychological, and biological. Washington: American Psychological Association Press, 2012:111-30.

14 Parry R. Video-based conversation analysis. In: Bourgeault I, DeVries R, Dingwall R, eds. Sage handbook of qualitative methods in health research. London: Sage, 2010:373-96.

15 Heritage J. The interaction order and clinical practice: some observations on dysfunctions and action steps. Patient Educ Couns 2011;84:338-43.

16 Parry R, Land V. Systematically reviewing and synthesising evidence from conversation analytic and related discursive research to inform healthcare communication practice and policy: an illustrated guide. BMC Med Res Methodol 2013;13:69. http://www.biomedcentral.com/1471-2288/13/69

17 Petticrew M, Roberts H. Systematic reviews in the social sciences: a practical guide. New York: John Wiley, 2006.

18 Pawson R, Greenhalgh T, Harvey G, et al. Realist review-a new method of systematic review designed for complex policy interventions. J Health Serv Res Policy 2005;10(Suppl 1):21-34.

19 Parry R, Land V, Seymour J. Communicating face-to-face about sensitive future matters including end of life: a systematic review of evidence from fine-grained observational research. York: PROSPERO: International prospective register of systematic reviews: CRD42011001626, 2012.

http://www.crd.york.ac.uk/PROSPERO/display_record.asp? ID $=$ CRD42011001626

20 Greenhalgh T, Peacock R. Effectiveness and efficiency of search methods in systematic reviews of complex evidence: audit of primary sources. BMJ 2005;331:1064-5.

21 Parry R, Land V. Additional files: systematically reviewing and synthesising evidence from conversation analytic and related discursive research to inform healthcare communication practice and policy: an illustrated guide. BMC Med Res Methodol 2013;13:69. http://www.biomedcentral.com/ 1471-2288/13/69/additional

22 Barnett-Page E, Thomas J. Methods for the synthesis of qualitative research: a critical review. BMC Med Res Methodol 2009;9:59.

23 Alhuwalia SC, Levin JR, Lorenz KA, et al. "There's no cure for this condition": how physicians discuss advance care planning in heart failure. Patient Educ Couns 2013;91:200-5.

24 Beach W. Managing optimism. In: Glenn P, LeBaron C, Mandelbaum J, eds. Studies in language and social interaction. Mahwah, NJ: Lawrence Erlbaum Associates, 2003:175-94.

25 Leydon G. 'Yours is potentially serious but most of these are cured': optimistic communication in UK outpatient oncology consultations. Psychooncology 2008;17:1081-8.

26 Lutfey K, Maynard D. Bad news in oncology: how physician and patient talk about death and dying without using those words. Soc Psychol Q 1998;61:321-41.

27 Maynard D, Frankel R. Indeterminacy and uncertainty in the delivery of diagnostic news in internal medicine: a single case analysis. In: Glenn P, LeBaron CD, Mandelbaum J, eds. Studies 
in language and social interaction-in honor of Robert Hopper. Mahwah, NJ: Lawrence Erlbarum Associates, 2003:393-410.

28 Miller G, Silverman D. Troubles talk and counseling discourse: a comparative study. Sociol Q 1995;36:725-47.

29 Norton S, Metzger M, DeLuca J, et al. Palliative care communication: linking patients' prognoses values, and goals of care. Res Nurs Health 2013;36:582-90.

30 Peräkylä A, Bor R. Interactional problems of addressing "Dreaded Issues" in HIV-counselling. AIDS Care 1990;2:325-38.

31 Peräkylä A. Invoking a hostile world: discussing the patient's future in AIDS counselling. Text 1993;13:291-316.

32 Peräkylä A. AIDS counselling: institutional interaction and clinical practice. Cambridge: Cambridge University Press, 1995:232-86.

33 Rodriguez KL, Gambino FJ, Butow P, et al. Pushing up daisies: implicit and explicit language in oncologist-patient communication about death. Support Care Cancer 2007;15:153-61.

34 Rodriguez KL, Gambino FJ, Butow P, et al. 'It's going to shorten your life': framing of oncologist-patient communication about prognosis. Psychooncology 2008;17:219-25.

35 Sarangi S, Clarke A. Constructing an account by contrast in counselling for childhood genetic testing. Soc Sci Med 2002;54:295-308.

36 Sarangi S. The spatial and temporal dimensions of reflective questions in genetic counselling. In: Freed A, Ehrlich S, eds. "Why Do You Ask?": the function of questions in institutional discourse. Oxford: Oxford University Press, 2010:235-55.

37 Silverman D, Peräkylä A. AIDS counselling: the interactional organisation of talk about 'delicate' issues. Sociol Health Illn 1990;12:293-318.

38 Speer S, Parsons C. Gatekeeping gender: some features of the use of hypothetical questions in the psychiatric assessment of transsexual patients. Discourse Soc 2006;17:785-812.

39 Speer S. Pursuing views and testing commitments: hypothetical questions in the psychiatric assessment of transsexual patients. In: Freed A, Ehrlich S, eds. Why do you ask: the function of questions in institutional settings. Oxford: Oxford University Press, 2010:133-8.
40 Tulsky JA, Fischer GS, Rose MR, et al. Opening the black box: how do physicians communicate about advance directives? Ann Intern Med 1998;129:441-9.

41 Wade J, Donovan JL, Athene Lane J, et al. It's not just what you say, it's also how you say it: opening the 'black box' of informed consent appointments in randomised controlled trials. Soc Sci Med 2009;68:2018-28.

42 Parry R, Land V, Seymour J. Abstract: Communicating face to face about sensitive future matters including end of life: a systematic review of evidence from fine-grained observational research (Poster presentation at the European Association for Palliative Care Conference, Norway) Palliat Med 2012;26:539.

43 Anderson D. "What you'll say is...." represented voice in organizational change discourse. J Organ Change Manag 2005;18:63-77.

44 Dingwall R, Murphy E, Greatbatch D, et al. Catching goldfish: quality in qualitative research. J Health Serv Res Policy 1998;3:167-72.

45 Fletcher I. Patterns of verbal interaction between health professionals and cancer patients. University of Manchester, 2006.

46 Heritage J. Questioning in medicine. In: Freed A, Ehrlich S, eds. 'Why do you ask?': the function of questions in institutional discourse. Oxford University Press, 2009:42-68.

47 Stivers T, Enfield NJ, Brown P, et al. Universals and cultural variation in turn-taking in conversation. Proc Natl Acad Sci 2009;106:10587-92. http://www.pnas.org/content/106/26/ 10587.full

48 Jefferson G. Notes on a possible metric which provides for a 'standard maximum' silence of approximately one second in conversation. In: Roger D, Bull P, eds. Conversation: an interdisciplinary perspective. Clevedon. UK: Multilingual Matters, 1988:166-96.

49 Graugaard P, Rogg L, Eide H, et al. Ways of providing the patient with a prognosis: a terminology of employed strategies based on qualitative data. Patient Educ Couns 2011;83:80-6.

50 Robinson J, Hoover D, Venetis M, et al. Consultations between patients with breast cancer and surgeons: a pathway from patient-centred communication to reduced hopelessness. J Clin Oncol 2013;31:351-8. 